\title{
Structure and Stress in Au/Cu Two-Layer System during Annealing at Different Temperature
}

\author{
D. CHOCYK* \\ Department of Applied Physics, Lublin University of Technology, Nadbystrzycka 38, 20-618 Lublin, Poland \\ In this work, the $\mathrm{Au} / \mathrm{Cu}$ two-layer systems, with the total thickness equal to $30 \mathrm{~nm}$ are studied. The two-layer \\ systems were deposited by thermal evaporation in a UHV system on the silicon substrate at room temperature. \\ After deposition the samples were annealed. We examined samples subjected to thermal cycle with the different \\ maximum temperature. The X-ray diffraction and X-ray reflectometry are performed for systems before and after \\ annealing. It was found that during the cycle of annealing above $150{ }^{\circ} \mathrm{C}$ starts process of penetration of the Au \\ layer by $\mathrm{Cu}$ atoms results in alloying. In $\mathrm{Au} / \mathrm{Cu}$ systems, the final layer is the ordered $\mathrm{Au} / \mathrm{Cu}_{3}$ phase.
}

DOI: 10.12693/APhysPolA.130.1118

PACS/topics: 68.60.Bs, 68.60.Dv, 68.65.Ac

\section{Introduction}

Devices based on systems consisting of thin layers are widespread in microelectronic technologies. Many physical properties of layered structures are strongly dependent on the stress and structure. Therefore, detailed studies of the relation between the structure and the stress are therefore essential. In particular, the two-layer systems of copper and metal or silicides deposited on semiconductor are very attractive due to a potential use for diffusion barriers and contacts $[1,2]$. Recently, there are many studies of the $\mathrm{Au} / \mathrm{Cu}$ two-layer systems [3-6]. These works are focused on diffusion during thermal annealing and alloying and mechanical characteristic of these systems. Moreover, in ultra large-scale integration devices, some metallization processes are required. As a result, the interconnect lines formed may undergo thermal cycles between room temperature and about designated temperature as subsequent layers of metallization are formed. Therefore, studies of $\mathrm{Au} / \mathrm{Cu}$ two-layers are very important for achieving stable and long life-time devices.

In this work, the $\mathrm{Au} / \mathrm{Cu}$ two-layer structures, with the total thickness equal to $30 \mathrm{~nm}$ are studied. Experimental observation of the average force $F$ per width $w$ (i.e. $F / w)$ measurements during annealing, X-ray reflectivity (XRR), and X-ray diffraction (XRD) measurements of $\mathrm{Au} / \mathrm{Cu}$ two-layer systems are presented.

\section{Experimental}

The $\mathrm{Au} / \mathrm{Cu}$ two-layer systems were deposited at room temperature by thermal evaporation under UHV. The systems were deposited on $100 \mu \mathrm{m} \mathrm{Si}(001)$ substrates and substrate dimension was always kept at $20 \mathrm{~mm} \times 10 \mathrm{~mm}$. Before the deposition, after standard cleaning in ultrasonic washer in acetone and ethanol,

*e-mail: d.chocyk@pollub.pl a substrate was dried in nitrogen gas and was immediately loaded into a UHV system. The base pressure in the deposition chamber was equal to $2 \times 10^{-9} \mathrm{hPa}$. The thickness of deposited layer was controlled by quartz-crystal microbalance.

The process of deposition was carried out with $1 \mathrm{~min}$ break between deposition of $\mathrm{Cu}$ and $\mathrm{Au}$ layers. A break was applied to the relaxation of the copper layer. Both layers $\mathrm{Cu}$ and $\mathrm{Au}$ was deposited with the constant thickness of $15 \mathrm{~nm}$. Four samples were prepared in the same manner. Three samples were subjected to annealing under vacuum. Samples were horizontally positioned onto annealing table in $\mathrm{HV}$ annealing chamber with base pressure $2 \times 10^{-7} \mathrm{hPa}$. The samples were annealed and cooled with the rate $10^{\circ} \mathrm{C} / \mathrm{min}$ ranging from room temperature (RT) to 150,290 , and $400^{\circ} \mathrm{C}$, respectively. Temperature was monitored by thermocouple.

Stress in heated thin films was calculated by measuring the change in curvature radius using the Stoney formula [7]. In annealing systems, the scanning laser method described by Flinn et al. [8] was applied in situ to the evolution of stresses during annealing. The details of the measurement setups have been described earlier [9]. Change of the substrate curvature during the film growth is proportional to $F / w$. Positive values of $F / w$ are related to tensile stress whereas negative values - to compressive film stress. However, positive value of a slope of the curve $F / w$ corresponds to tensile incremental stress, even if the average stress is negative. Negative value of the slope corresponds to increase of compressive stress even if the absolute stress value is positive.

The effect of heat treatments on microstructure was studied by X-ray methods. The X-ray diffractometer (PANalytical, Empyrean) was used with $\mathrm{Cu} K_{\alpha}$ radiation $(\lambda=0.15418 \mathrm{~nm})$ at $40 \mathrm{kV}$ and $30 \mathrm{~mA}$. Samples were studied by X-ray reflectometry and X-ray diffraction in $\theta-2 \theta$ geometry.

\section{Results and discussion}

Figure 1 shows the evolution of stress versus temperature for $\mathrm{Au} / \mathrm{Cu}$ bilayers in thermal cycles for the 
maximum temperature of annealing: 150, 290, and $400^{\circ} \mathrm{C}$, respectively. In all cycles, the linear changes of stress in compressive direction from RT to about $75^{\circ} \mathrm{C}$ are observed. Generally, the strain is the sum of plastic and elastic strains. However, in low temperatures the main role plays only elastic strain. In all samples, as long as the system behaves elastically the stress evolution is a linear function of temperature. Next, the data deviate from straight line. A nonlinear evolution of the stress as a function of the temperature is the result of different plastic deformation processes occurring in the films [9]. During cooling the films contract more than silicon substrate which results in a stress evolution in the tensile direction with the exception of the system subjected to heating to $290^{\circ} \mathrm{C}$. For this system the stress returns to initial value. Restoring the initial value of stress suggests that the system deposited on the substrate has changed its elastic properties in comparison to the system before annealing.

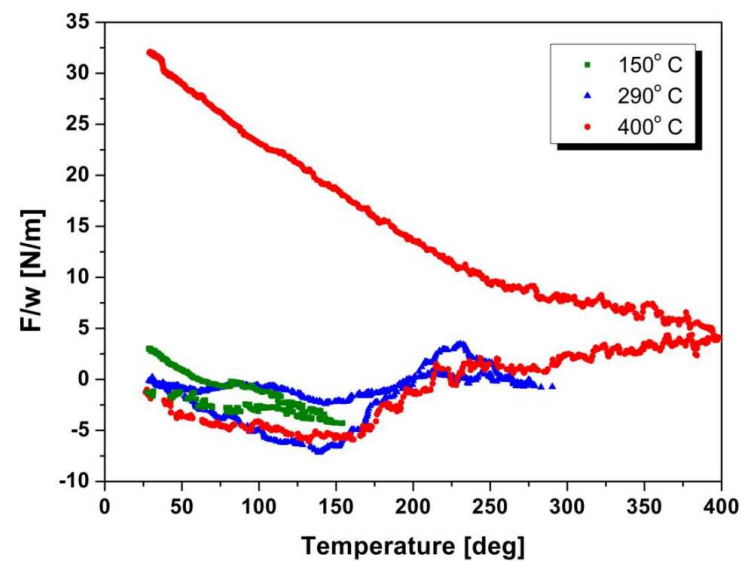

Fig. 1. The total force per unit width $F / w$ dependence on temperature during annealing and cooling the $\mathrm{Au} / \mathrm{Cu}$ two-layer system in range of the room temperature and $150,290,400^{\circ} \mathrm{C}$, respectively.

TABLE I

Data obtained from fitting the X-ray reflectometry curves.

\begin{tabular}{c|c|c|c}
\hline \hline Layer & Density $\left[\mathrm{g} / \mathrm{cm}^{3}\right]$ & Thickness $[\mathrm{nm}]$ & Roughness $[\mathrm{nm}]$ \\
\hline \multicolumn{4}{c}{ RT } \\
\hline $\mathrm{Au}$ & 18.72 & 19.6 & 1.29 \\
$\mathrm{Cu}$ & 9.42 & 8.7 & 1.19 \\
\hline \multicolumn{4}{c}{ max. temp. $150^{\circ} \mathrm{C}$} \\
\hline $\mathrm{Au}$ & 17.72 & 19.9 & 1.17 \\
$\mathrm{Cu}$ & 9.89 & 10.2 & 1.12 \\
\hline \multicolumn{4}{c}{$\max$. temp. $290^{\circ} \mathrm{C}$} \\
\hline $\mathrm{Au}$ & 16.64 & 21.9 & 0.91 \\
$\mathrm{Cu}$ & 15.39 & 7.5 & 0.76 \\
\hline \multicolumn{4}{c}{$\max$. temp. $400^{\circ} \mathrm{C}$} \\
\hline $\mathrm{Au}$ & 16.41 & 31.7 & 1.45 \\
$\mathrm{Cu}$ & 18.31 & 0.3 & 0.64
\end{tabular}

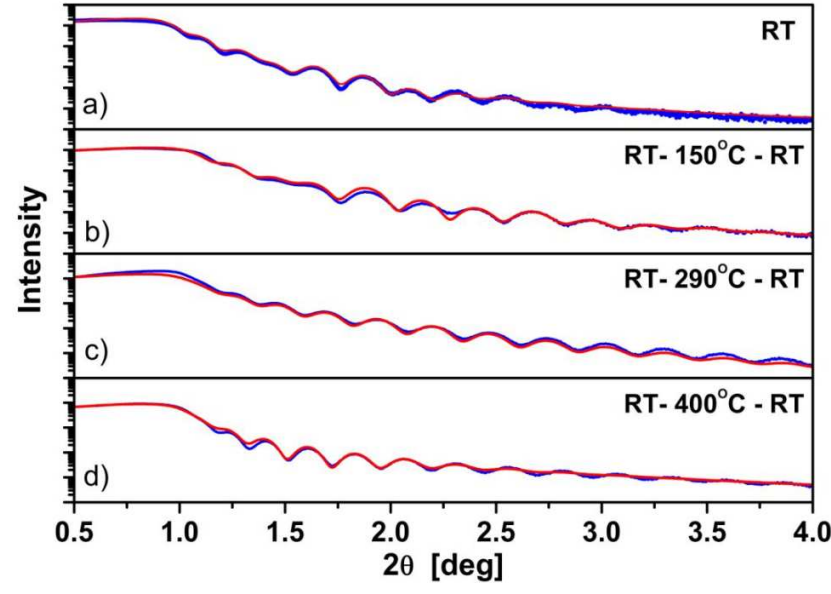

Fig. 2. X-ray reflectometry measurements (blue lines) and fitting curves (red lines) for $\mathrm{Au} / \mathrm{Cu}$ (a) before and after annealing and cooling in range of the room temperature, and (b) $150{ }^{\circ} \mathrm{C}$, (c) $290^{\circ} \mathrm{C}$, and (d) $400^{\circ} \mathrm{C}$, respectively.

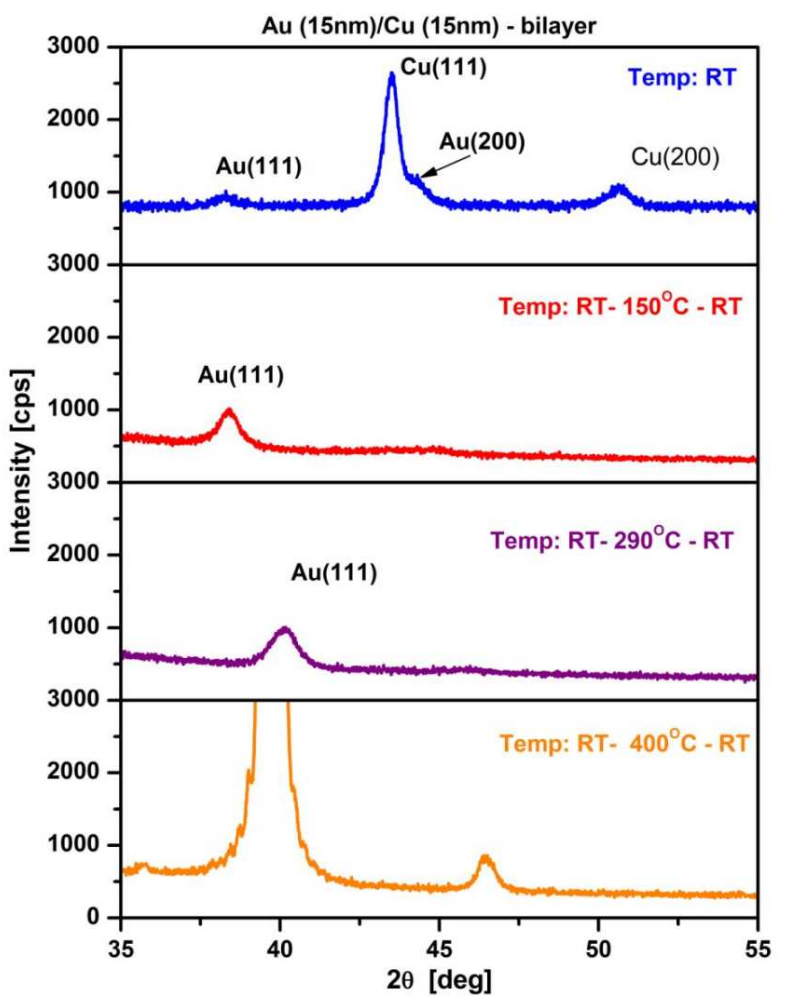

Fig. 3. X-ray diffraction measurements for $\mathrm{Au}(15 \mathrm{~nm}) / \mathrm{Cu}(15 \mathrm{~nm})$ bilayer (a) before and after annealing and cooling in range of the room temperature, and (b) $150{ }^{\circ} \mathrm{C}$, (c) $290^{\circ} \mathrm{C}$, and (d) $400^{\circ} \mathrm{C}$, respectively.

Figure 2 presents the X-ray reflectometry curves and fitting curves obtained for $\mathrm{Au} / \mathrm{Cu}$ two-layer systems before and after annealing at $150,290,400^{\circ} \mathrm{C}$, respectively. For all samples the characteristic oscillations of the intensity are well detectable. The parameters obtained from fitting X-ray reflectometry curves are presented in 
Table I. From fitting of the XRR curves the resulting value of $\mathrm{Au}$ layer thickness increases with rising the maximum annealing temperature. In contrast, the density decreased with increase of the maximum annealing temperature. The opposite situation is for $\mathrm{Cu}$ layer. For the $\mathrm{Au} / \mathrm{Cu}$ system heated to of $400{ }^{\circ} \mathrm{C}$, the thickness of the $\mathrm{Au}$ layer with a reduced density corresponds to the total thickness of the system and $\mathrm{Cu}$ layer shrinks to zero thickness. This result suggests that, in place of the twolayer system, there is formed a single-layer system. This layer is an alloy resulting from the materials of deposited layers. In the order to study formed layer XRD measurements were carried out.

The $\theta-2 \theta$ X-ray diffraction profiles for as deposited and annealed $\mathrm{Au} / \mathrm{Cu}$ two-layer systems are shown in Fig. 3. In the XRD profiles obtained for as deposited $\mathrm{Au} / \mathrm{Cu}$ system (Fig. 3a), one can distinguish peaks at $2 \theta=38.20^{\circ}, 44.28^{\circ}$ from structure of Au layer and peaks at $2 \theta=43.46^{\circ}, 50.57^{\circ}$ from structure of $\mathrm{Cu}$ layer. High intensity of $\mathrm{Cu}(111)$ peak compared to $\mathrm{Cu}(200)$ peak indicates preferred [111] orientation of the $\mathrm{Cu}$ layer. But, weak intensity of peaks from the $\mathrm{Au}$ layer suggested a large disorder in gold layer. For system annealed to $150^{\circ} \mathrm{C}$ one can see increase of intensity of $\mathrm{Au}(111)$ peak and complete lack of $\mathrm{Cu}$ peaks. This suggested increase of crystalline order in $\mathrm{Au}$ layer and increase of disorder in $\mathrm{Cu}$ layer and that in the system exists a large volume of disordered structure. However, for systems annealed to $290^{\circ} \mathrm{C}$ and $400{ }^{\circ} \mathrm{C}$ one can observe peak approximately at $2 \theta=40.0^{\circ}$ and $46.4^{\circ}$ (Fig. 3d) from $\mathrm{AuCu}_{3}$ phase [5] formed during annealing. This also confirms the results obtained from fitting the X-ray reflectometry profiles. This confirms that the area of interface can be treated as a new layer that forms during the annealing cycle, and is consistent with the results obtained by Benazzouz et al. [10] for the $\mathrm{Au} / \mathrm{Cu}$ systems.

\section{Conclusions}

From the results of this study of $\mathrm{Au} / \mathrm{Cu}$ two-layer systems presented here the following conclusions can be drawn:

1. During the annealing the process of penetration of the $\mathrm{Au}$ layer by $\mathrm{Cu}$ atoms starts above $150{ }^{\circ} \mathrm{C}$ and results in alloying.

2. For temperatures lower than $290^{\circ} \mathrm{C}$ annealing results in disordered structure alloy structure.

3. Above $290{ }^{\circ} \mathrm{C}$ the $\mathrm{Au} / \mathrm{Cu}$ bilayers form ordered $\mathrm{AuCu}_{3}$ alloy.

\section{References}

[1] V.L. Devi, I. Jyothi, V.R. Reddy, Ch.-J. Choi, Open Appl. Phys. J. 5, 1 (2012).

[2] Y. Yu, L. Zeng, Y. Jiang, J. Jie, IEEE Electron Dev. Lett. 34, 810 (2013)

[3] J.W. Elmer, T.A. Palmer, E.D. Specht, J. Vac. Sci. Technol. A 24, 978 (2006).

[4] M. Reiner, P. Pikart, C. Hugenschmidt, J. Alloys Comp. 64, 515 (2014).

[5] A. Tynkova, G.L. Katona, G.A. Langer, S.I. Sidorenko, S.M. Voloshko, D.L. Beke, Beilstein J. Nanotechnol. 5, 1491 (2014).

[6] Z.-P. Luo, G.-P. Zhang, R. Schwaiger, Scr. Mater. 107, 67 (2015).

[7] G.G. Stoney, Proc. R. Soc. Lond. Ser. A 82, 172 (1909).

[8] D.P.A. Flinn, D.S. Gardner, W.D. Nix, IEEE Trans. Electron. Dev. 34, 689 (1987).

[9] D. Chocyk, A. Proszynski, G. Gladyszewski, Microelect. Eng. 85, 2179 (2008).

[10] C. Benazzouz, N. Benouattas, A. Bouabellou, Nucl. Instrum. Methods Phys. Res. B 230, 571 (2005). 